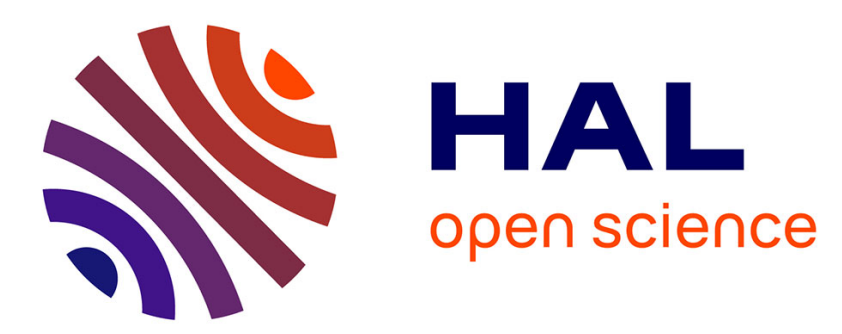

\title{
Influence of Coating on the Thermal Fatigue Resistance of a Ni-based Superalloy
}

Catherine Mabru, N. Stephan, Rémy Chieragatti

\section{To cite this version:}

Catherine Mabru, N. Stephan, Rémy Chieragatti. Influence of Coating on the Thermal Fatigue Resistance of a Ni-based Superalloy. International Journal of Damage Mechanics, 2006, 15 (4), pp.375391. 10.1177/1056789506058049 . hal-00571149

\section{HAL Id: hal-00571149 https://hal.science/hal-00571149}

Submitted on 1 Mar 2011

HAL is a multi-disciplinary open access archive for the deposit and dissemination of scientific research documents, whether they are published or not. The documents may come from teaching and research institutions in France or abroad, or from public or private research centers.
L'archive ouverte pluridisciplinaire HAL, est destinée au dépôt et à la diffusion de documents scientifiques de niveau recherche, publiés ou non, émanant des établissements d'enseignement et de recherche français ou étrangers, des laboratoires publics ou privés. 


\title{
Influence of Coating on the Thermal Fatigue Resistance of a Ni-based Superalloy
}

\author{
C. MABru,* N. Stephan And R. Chieragatti \\ Département Génie Mécanique \\ Ecole Nationale Supérieure d'Ingénieurs de Constructions Aéronautiques \\ 1 Place Emile Blouin 31056 Toulouse Cedex 5, France
}

\begin{abstract}
In this article, the influence of a M-CrAlY polycrystalline coating on the thermal fatigue behavior of a nickel-base superalloy has been investigated. A special device using a rotating bending machine and two thermal sources has been used to perform thermomechanical tests. The two thermal sources have been set to obtain temperature variations between 750 and $1120^{\circ} \mathrm{C}$ in the central part of the specimens, with a frequency of $0.1 \mathrm{~Hz}$. The results show a deleterious effect of the coating on the fatigue resistance. Numerical simulations have been carried out on SAMCEF to determine the thermomechanical field of the so-tested specimens. Calculated thermomechanical cycles of critical sites are associated with microstructure evolution and damage by cracking observed on the specimens. Damage mechanisms related to the presence of the coating are discussed.
\end{abstract}

KEY WORDS: thermomechanical fatigue, coating, Ni-base superalloy.

\section{INTRODUCTION}

ICKEL-BASE SUPERALLOYS ARE among the most currently used 1 materials for high-temperature components in gas turbines because of their good high-temperature properties. However, because of their limited oxidation resistance at elevated temperatures, their strength potential can only be fully exploited by the application of oxidation-resistant protective coatings. Owing to thermal gradients arising during the transient regime, thermomechanical fatigue, which combines complex thermal and

*Author to whom correspondence should be addressed. E-mail: cmabru@ensica.fr

International Journal of DAMAge Mechanics, Vol. 15-October 2006 
mechanical loading, is the main damage limiting the life of turbine blades. Moreover, the presence of a coating modifies the behavior of the substrate material subjected to this type of loading. However, this influence is variable (Lautridou et al., 1996; Rémy et al., 1996; Kowalewski and Mughrabi, 2000; Zamrik and Renauld, 2000). Hence, specific description and modeling of the damage mechanisms associated with a couple coating/substrate is needed.

Hereafter, the influence of a NiCoCrAlYTa coating on the thermal fatigue resistance of the nickel-base superalloy MC2 is investigated. Testing is completed on a special device, which has been developed in previous work (Paun and Chieragatti, 2000), to impose thermal and mechanical loading at relatively high frequencies (compared to usual thermomechanical fatigue tests) on a portion of a tubular specimen. This device is based on a rotating bending machine with two external high and low temperature sources. To simulate a representative critical loading for this study, the chosen thermal cycle ranges from 750 to $1120^{\circ} \mathrm{C}$ in the central part of the specimens. Thermal stresses are important due to the high temperature gradients on the samples. An estimate of their values can be reached by numerical calculations. The previous numerical modeling associated with this kind of experiment (Paun and Chieragatti, 2000) has been improved to match with coated specimens. After a thermal calculation, which provides the temperature map of the whole specimen, mechanical calculations are completed and lead to the thermomechanical field of the sample during a cycle. Attention is paid to the thermomechanical cycle of the central part of non-coated and coated specimens as this part is proved to be the most critical site (higher stresses at highest temperatures). The calculated thermomechanical cycles and observations of microstructural evolution and damage of the tested specimens are then collated. This allows a proposal of damage mechanisms related to the presence of coating and to highlight improvements that are needed for a more representative numerical simulation at the same time.

\section{THERMOMECHANICAL FATIGUE TEST RIG}

The test rig (Figure 1) is a rotating bending fatigue machine in which two thermal sources are incorporated. The heat source is a high frequency induction furnace whereas a cold air jet is used for cooling. This specimen is a hollow cylinder having inner and outer diameters of 11 and $13 \mathrm{~mm}$, respectively. The total length of the test specimen is $100 \mathrm{~mm}$. It is held in the machine at its two cylindrical ends. With a suitable application of heating/ cooling as well as of the rotating bending loading, high frequency 


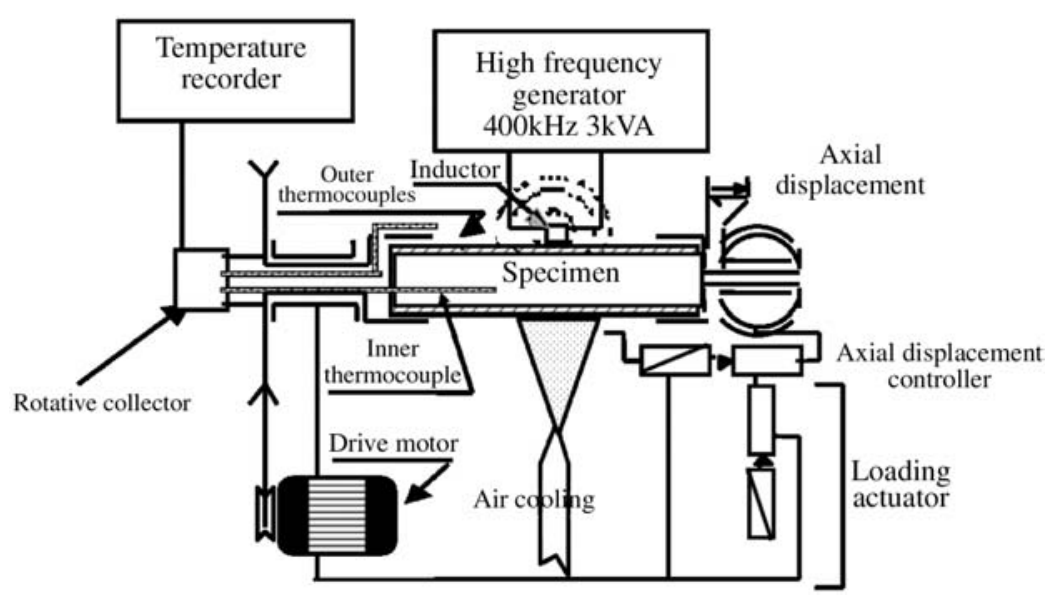

Figure 1. Schematic of thermomechanical fatigue test rig.

thermomechanical fatigue cycles are produced in a small portion of a generatrix of this test specimen. Four thermocouples are fixed on the same surface generatrix, $\approx 0,5,10$, and $15 \mathrm{~mm}$, respectively, away from the center of the most loaded zone. The temperature readings from all four thermocouples are recorded throughout the testing. The rotating frequency is $\approx 0.1 \mathrm{~Hz}$.

The applied deflection is controlled with the help of a displacement gauge placed at one end of the specimen. The two thermal sources are set to obtain temperature variations between 750 and $1120^{\circ} \mathrm{C}$ on the central thermocouple. The specimen is allowed to elongate axially during temperature field stabilization. As soon as the stable thermal cycle is attained, the axial displacement is blocked.

\section{NUMERICAL MODELING}

The test was simulated with the help of SAMCEF finite elements software using module MECANO-THERMAL for thermal calculations and MECANO-STRUCTURE for thermomechanical ones. MECANOTHERMAL is a program, which solves linear and nonlinear response problems of solid media, having thermal characteristics, which may vary with time and temperature, both in transient and steady state, within the framework of Fourier's assumption. All kinds of boundary conditions can be applied: imposed heat flux, convective and/or radiative exchange, and imposed temperature. Internal source distribution can also be prescribed. These loading modes can depend on temperature and/or time. Combinations of these loading are allowed within a single problem. 
MECANO-STRUCTURE is dedicated to the nonlinear analysis of structures. It is possible to perform static, quasi-static, or dynamic analysis. The material behavior, which is temperature-dependent can be linear, nonlinear elastic, elastoplastic, viscoelastic, and viscoplastic.

\section{Geometrical Model}

In the geometrical model, the nodes and meshes were defined on a cross section in cylindrical reference axes with 30 angular steps and then repeated axially at decreasing distance intervals while approaching the high thermal loading zone. This zone is situated at the half-length of the test specimen. Depth of the substrate and the coating is modeled respectively by 6 and 2 elements. Meshes are formed of quadrangle elements. These elements can be used for both thermal and mechanical analyses.

\section{Thermal Model}

This model is thoroughly described in a previous article (Paun and Chieragatti, 2000). The main conditions and results are reviewed here. Functions of heat transfer were associated with different facets of the geometrical model using MECANO-THERMAL. Four zones were considered for solving our problem (Figure 2).

\section{ZONE ZCC (FORCED CONVECTION ZONE)}

This is the central belt on which the convection caused by the cold air jet and the radiation through the air were simulated. Estimated to be four meshes wide, it covers an $8 \mathrm{~mm}$ distance along the specimen length. The value of the forced convection exchange coefficient has been determined from fluid mechanics law considering jet air speed and specimen diameter. In this study, the theoretical average value was $h_{\text {theo }}=175 \mathrm{~W} / \mathrm{m}^{2} \mathrm{~K}$. Spatial distribution of this coefficient around the specimen has been evaluated using Platz and Starr modeling and it takes into account the modification of airflow due to the presence of the inductor behind the cylinder (Paun, 1998).

\section{ZONE ZCL (FREE CONVECTION ZONE)}

This zone comprises two belts of $3 \mathrm{~mm}$ width each on both sides of the ZCC and serves as the buffer zone between ZCC and ZL.

\section{ZONE ZL (FREE ZONE)}

This covers the remaining test specimen where heat transfers due to convection and radiation are small. 


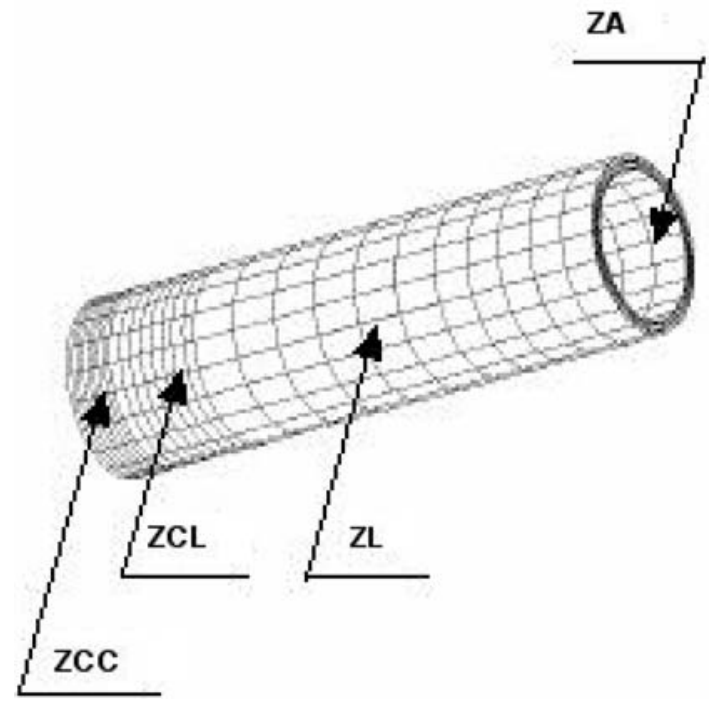

Figure 2. Schematic of the geometrical and thermal model (half specimen).

ZONE ZA (ADIABATIC ZONE)

It comprises all the internal facets of the test specimen, where heat transfer is considered to be negligible.

Underneath the ZCC and ZCL zones, volume elements are defined to absorb the power generated by the inductor. The subsequent internal heat source depends on the distance between the volume element and the source of induction. This induction source is considered linear and perpendicular to the specimen axis. Spatial power distribution is implemented by means of a coefficient for each element. An average coefficient is needed to represent the inductor power that may vary with the temperatures to be reached. In this study, the theoretical value of this coefficient is $\mathrm{Pi}=0.85$.

Fourier's law is used for the heat transfer in conduction and Fick's law is used for convection. Radiation is taken into account using Boltzmann's law. No thermal resistance is considered between the coating and the substrate.

Finally, once the thermal properties of the materials are defined, the only parameters to be changed in this model are the two coefficients related respectively to the forced convection exchange $(h)$ and to the inductor power (Pi).

\section{Simulation of Cycles}

Rotation of the specimen with respect to the boundary conditions as it occurs for a cycle during the test is not possible in SAMCEF. Therefore, 


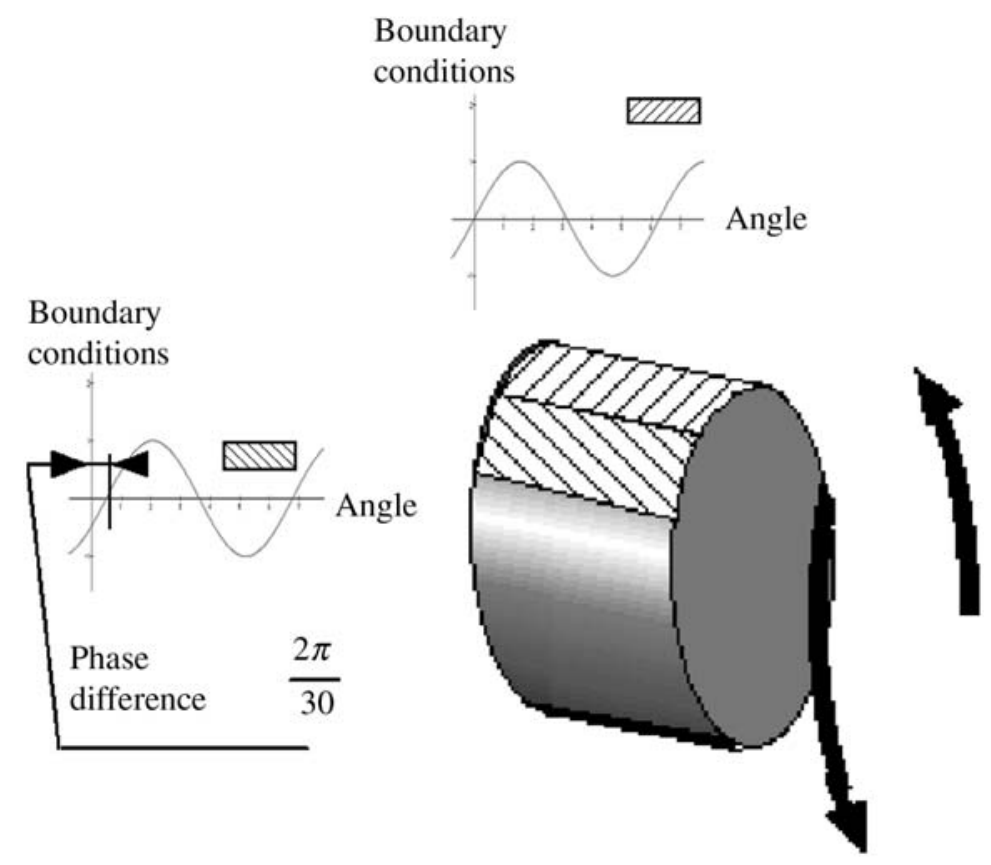

Figure 3. Modeling of the specimen rotation by introducing a phase difference in the boundary conditions.

in the simulation, it is the boundary conditions that are time-dependent to represent a cycle in $10 \mathrm{~s}$ (Figure 3). Every ZCC and ZCL type zone receives a variable thermal flux depending on its position on the generatrix and on the circumference. The same is true for volume element defined to absorb induction power. Two circumferencewise adjacent zones receive an equal thermal flux but out of phase (representative of specimen rotation). Two lengthwise adjacent zones receive unequal thermal flux but in phase (representative of spatial distribution at a given time). Since the stabilized conditions are not obtained right from the first cycle, it was necessary to calculate the temperature evolution cycle after cycle. A software program for temperature feedback was developed. It takes temperature distribution at the end of every cycle and inputs it as the initial conditions of the next cycle.

\section{Simulation of Mechanical Loading}

When the specimen thermal field is calculated using a MECANOTHERMAL module, it is translated into a MECANO-STRUCTURE 
module. Nonlinear calculations of thermal and mechanical loadings were carried out using this module. The load on the structure is applied in small increments but thermal loading is applied at the first increment. At every increment of load, the nonlinear system of equations is solved using the Newton-Raphson method. Loading is applied only once on the specimen model, which means that no cyclic evolution in stress-strain behavior was taken into account.

\section{MATERIALS}

The tubular specimens are made of monocrystalline Ni-base superalloy MC2 whose composition is presented in Table 1.

The crystallographic $\langle 001\rangle$ direction is parallel to the longitudinal axis of the specimens. Microstructure of this alloy consists of cubical $\gamma^{\prime}$ particles (volume content roughly $60 \%$ ) having an average size of $0.4 \mu \mathrm{m}$. The mechanical anisotropy of this kind of material is well illustrated in Table 2 (Merval, 2002).

For numerical simulation, anisotropy is defined by the 21 terms of the lower triangular Hooke matrix $\overline{\bar{C}}$, such as $\underline{\sigma}=\underline{C}\left(\underline{\varepsilon}-\underline{\varepsilon}_{\mathrm{th}}\right)$. For symmetry reasons, the matrix is, in our case, reduced to three independent terms: $C_{1111}, C_{1122}$, and $C_{2323}$ (see Table 3 (Merval, 2002)). Anisotropy has

Table 1. Nominal composition of MC2 (wt\%).

\begin{tabular}{lcccccc}
\hline Co & Cr & W & Al & Ta & Mo & Ti \\
\hline 5.08 & 7.89 & 7.99 & 5.05 & 5.96 & 2.11 & 1.49 \\
\hline
\end{tabular}

Table 2. Young's modulus of a nickel-base superalloy at room temperature for different crystallographic directions.

\begin{tabular}{lccc}
\hline Direction & $\langle\mathbf{0 0 1}\rangle$ & $\langle\mathbf{0 1 1}\rangle$ & $\langle\mathbf{1 1 1}\rangle$ \\
\hline$E(\mathrm{GPa})$ & 128 & 230 & 302 \\
\hline
\end{tabular}

Table 3. MC2 Hooke matrix terms as a function of temperature.

\begin{tabular}{lcccrr}
\hline $\boldsymbol{T}\left({ }^{\circ} \mathbf{C}\right)$ & $\mathbf{2 0}$ & $\mathbf{5 0 0}$ & $\mathbf{7 0 0}$ & $\mathbf{1 0 5 0}$ & $\mathbf{1 3 0 0}$ \\
\hline$C_{1111}(\mathrm{GPa})$ & 239 & 219 & 208 & 170 & 140 \\
$C_{1122}(\mathrm{GPa})$ & 140 & 121 & 114 & 97 & 77 \\
$C_{2323}(\mathrm{GPa})$ & 143 & 136 & 131 & 112 & 88 \\
\hline
\end{tabular}


to be taken into account because the thermal stresses are induced by differential thermal strain via Young's modulus. Neglecting anisotropy would lead to a misevaluation of thermal stresses and especially the biaxial ratio.

Only elastic properties are needed as yield stress at high temperature is far more important than thermal stresses induced in the tests $\left(\sigma_{\mathrm{y}}>1000 \mathrm{MPa}\right)$.

In Tables 4 and 5, other mechanical and thermal properties of MC2 that do not depend on the crystallographic orientations are presented as a function of temperature.

Some of the specimens were coated by electrodeposition with polycrystalline NiCoCrAlYTa whose composition is presented in Table 6. The coating material is fine-grained with a grain size of about $1 \mu \mathrm{m}$. The thickness of the coating on the specimen is about $70 \mu \mathrm{m}$.

Mechanical and physical properties are isotropic for this coating (see Tables 7 and 8 (Boudot, 1999)). Thermal properties of the coating and the substrate are of the same order of magnitude: the coating does not act as a thermal barrier but only as a protection against oxidation. At last, it is important to note that for this alloy, the ductile/brittle transition temperature is roughly $600^{\circ} \mathrm{C}$; this implies the coating is in its ductile field during the tests (thermal cycle between 750 and $1120^{\circ} \mathrm{C}$ ).

Table 4. Thermal expansion coefficient of MC2 as a function of temperature (Merval, 2002).

\begin{tabular}{lccccccr}
\hline $\boldsymbol{T}\left({ }^{\circ} \mathbf{C}\right)$ & $\mathbf{2 0}$ & $\mathbf{5 0 0}$ & $\mathbf{6 0 0}$ & $\mathbf{8 0 0}$ & $\mathbf{1 0 0 0}$ & $\mathbf{1 1 0 0}$ & $\mathbf{1 3 0 0}$ \\
\hline$\alpha\left(10^{-5} / \mathrm{K}\right)$ & 1 & 1.3 & 1.32 & 1.47 & 1.6 & 1.7 & 1.8 \\
\hline
\end{tabular}

Table 5. Thermal conductivity $(\lambda)$ and calorific capacity $\left(C_{p}\right)$ of MC2 as a function of temperature (Merval, 2002).

\begin{tabular}{lccccccc}
\hline $\boldsymbol{T}\left({ }^{\circ} \mathbf{C}\right)$ & $\mathbf{2 0}$ & $\mathbf{5 0 0}$ & $\mathbf{6 0 0}$ & $\mathbf{8 0 0}$ & $\mathbf{1 0 0 0}$ & $\mathbf{1 1 0 0}$ & $\mathbf{1 3 0 0}$ \\
\hline $\mathrm{C}_{\mathrm{p}}(\mathrm{J} / \mathrm{kg} \mathrm{K})$ & - & 478 & 493 & 539 & 657 & 720 & - \\
$\lambda(\mathrm{W} / \mathrm{m} \mathrm{K})$ & 7.8 & 13.5 & 14.5 & 16.7 & 18.5 & 20 & 24 \\
\hline
\end{tabular}

Table 6. Average composition of the coating (wt\%).

\begin{tabular}{cccccc}
\hline $\mathrm{Ni}$ & Co & Cr & Al & Y & Ta \\
\hline 48 & 21 & 18 & 9 & 0 & 4 \\
\hline
\end{tabular}


Table 7. Young's modulus and thermal expansion coefficient of the coating as a function of temperature.

\begin{tabular}{lcccccc}
\hline $\boldsymbol{T}\left({ }^{\circ} \mathrm{C}\right)$ & $\mathbf{6 0 0}$ & $\mathbf{8 0 0}$ & $\mathbf{9 0 0}$ & $\mathbf{1 0 0 0}$ & $\mathbf{1 1 0 0}$ & $\mathbf{1 3 0 0}$ \\
\hline$E(\mathrm{GPa})$ & 146 & 125 & 110 & 90 & 75 & 42 \\
$\alpha\left(10^{-5} / \mathrm{K}\right)$ & 1.43 & 1.6 & 1.7 & 1.78 & 1.88 & 1.96 \\
\hline
\end{tabular}

Table 8. Thermal conductivity $(\lambda)$ and calorific capacity $\left(C_{p}\right)$ of the coating as a function of temperature.

\begin{tabular}{lcccccr}
\hline $\boldsymbol{T}\left({ }^{\circ} \mathrm{C}\right)$ & $\mathbf{2 0 0}$ & $\mathbf{4 0 0}$ & $\mathbf{6 0 0}$ & $\mathbf{8 0 0}$ & $\mathbf{1 0 0 0}$ & $\mathbf{1 2 0 0}$ \\
\hline$C_{\mathrm{p}}(\mathrm{J} / \mathrm{kg} \mathrm{K})$ & 460 & 490 & 525 & 550 & 640 & 720 \\
$\lambda(\mathrm{W} / \mathrm{m} \mathrm{K})$ & 12 & 14.7 & 19.6 & 26.5 & 36.5 & 45 \\
\hline
\end{tabular}

Table 9. Conducted tests and results.

\begin{tabular}{lcccc}
\hline No coating & No coating & Coating & Coating & Coating \\
\hline 1000 cycles & 10,000 cycles & 1000 cycles & 10,000 cycles & 10,000 cycles \\
No damage & Superficial damage & No damage & Deep cracking & Deep cracking \\
\hline
\end{tabular}

\section{RESULTS AND DISCUSSION}

Five specimens (two specimens without a coating, three with a coating) have been tested on the thermomechanical fatigue test rig already described. No external deflection was imposed. The two sources have been set to impose a thermal cycle between 750 and $1120^{\circ} \mathrm{C}$ in the central part of the specimens at a frequency of $0.1 \mathrm{~Hz}(1$ cycle in $10 \mathrm{~s})$. The steady-state regime is reached after 20 cycles.

Table 9 sums up the five tests and their results.

No damage was observed for the non-coated specimen at 1000 cycles. Observations of the non-coated specimen at 10,000 cycles show no cracks but superficial damage, essentially situated on the internal surface in the center part, consisting of oxide peeling and superficial cracking located in the oxide layer. Metallographic analysis of a longitudinal section in the center part reveals:

- $\gamma^{\prime}$ phase depletion on both internal and external surfaces

- coalescence of $\gamma^{\prime}$ phase precipitates, perpendicular to the external surface (see Figure 4)

- coalescence of $\gamma^{\prime}$ phase precipitates, parallel to the internal surface (see Figure 5). 


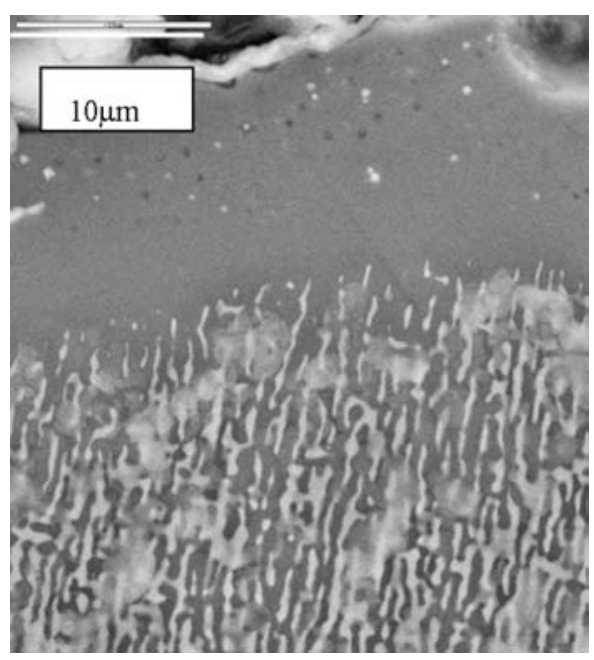

Figure 4. Specimen without coating - longitudinal section in the center part - external surface.

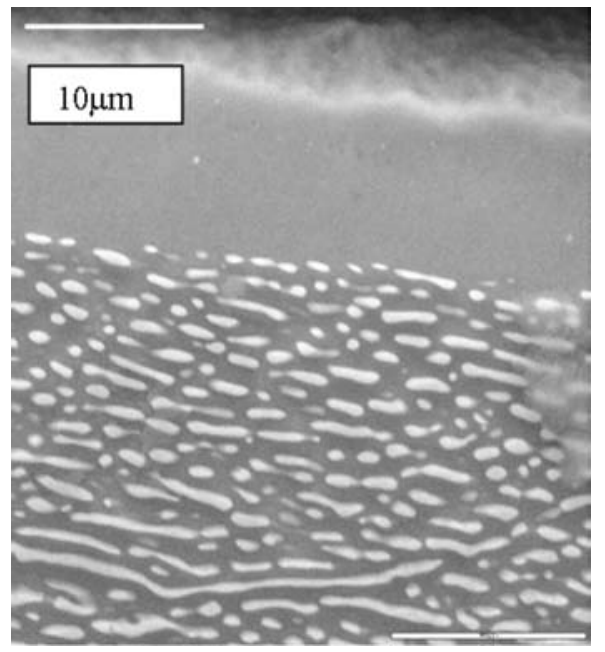

Figure 5. Specimen without coating - longitudinal section in the center part - internal surface.

For the coated specimens, no damage was observed at 1000 cycles. However, specimens loaded with 10,000 cycles exhibited deep cracks, perpendicular to the revolution axis, through the coating and the substrate in the internal surface. Crack density and crack depth are more important 


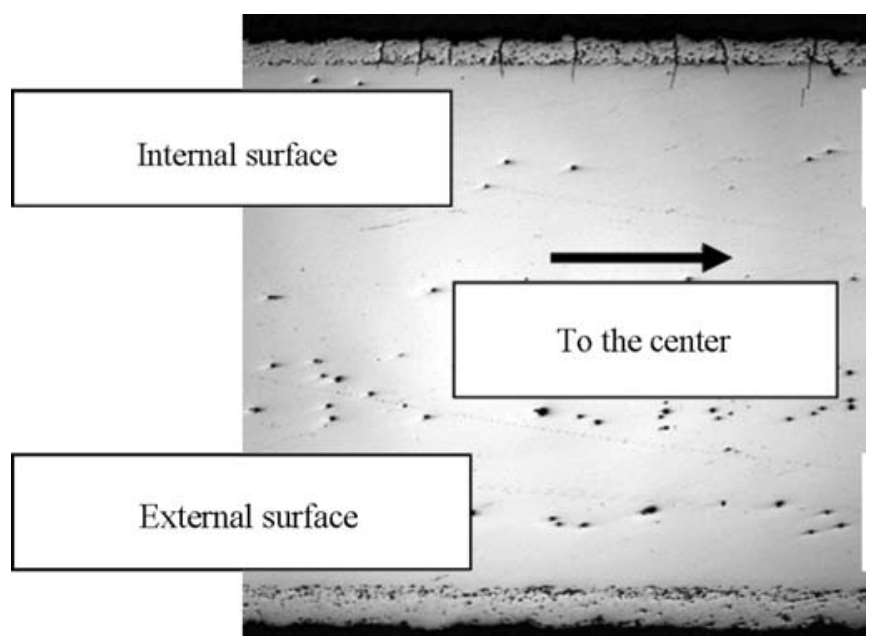

Figure 6. Section of coated specimen: $3 \mathrm{~mm}$ from the central part.

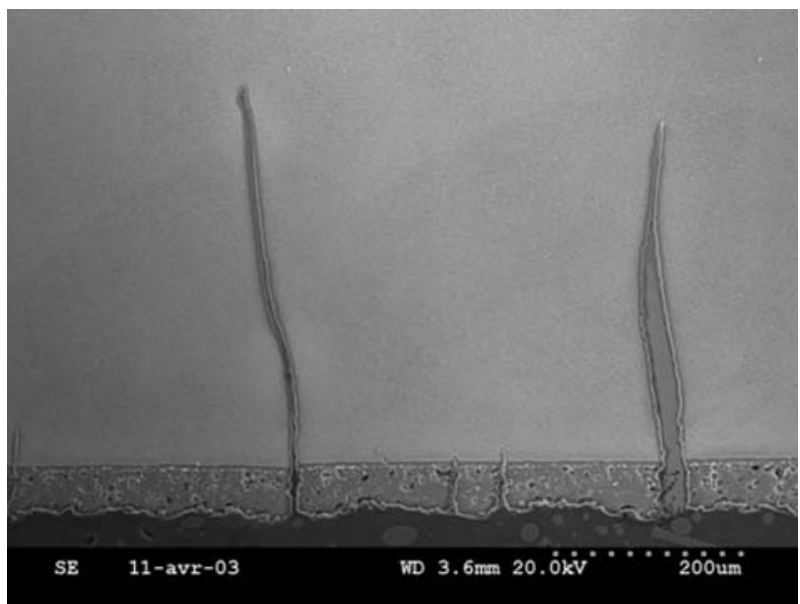

Figure 7. Main cracks inside the coated specimen - center part.

near the central part (see Figures 6 and 7). Crack surfaces are oxidized. $\gamma^{\prime}$ phase depletion is observed around these surfaces but not on the internal and external specimen surfaces where oxidation is prevented thanks to the coating. Oriented coalescence of $\gamma^{\prime}$ phase precipitates can also be seen, as noted for the non-coated specimens.

Numerical simulations have then been conducted to get an insight into the thermomechanical cycles of both types of specimens. Thermal calculations were first achieved to obtain a representative thermal cycle. 
The two numerical parameters related to the high temperature source (inductor power) and the low temperature source (forced convection exchange coefficient), respectively have been adjusted to fit the experimental data in the central part of the specimens. The so-obtained values are close to the theoretical ones: $h_{\text {num }}=160 \mathrm{~W} / \mathrm{m}^{2} \mathrm{~K}$ instead of $h_{\text {theo }}=175 \mathrm{~W} / \mathrm{m}^{2} \mathrm{~K}$, $\mathrm{Pi}=0.8$ instead of 0.85 . A comparison between the experimental thermal cycle (temperatures obtained by means of a thermocouple) and the numerically simulated one is presented in Figure 8, for the central part of the specimen.

It can be noted that not only are peak values similar but also that the shape of the cycle (slight asymmetry due to thermal inertia during cooling) is well respected. Good agreement between both cycles for one point of the specimen is not enough to be sure that the numerical simulation will give a representative temperature field. Validation of the model has been completed by comparing the temperature evolution during a cycle for other points of the specimens. These comparisons gave satisfactory results in terms of temperature values and phase differences between the thermal cycles at the center and at the other points. It is also important to mention that an important thermal gradient is observed (experimentally and numerically) along a generatrix of the specimen. When the center part is at $1120^{\circ} \mathrm{C}$, a point at $5 \mathrm{~mm}$ from the center on the same generatrix is at $930^{\circ} \mathrm{C}$.

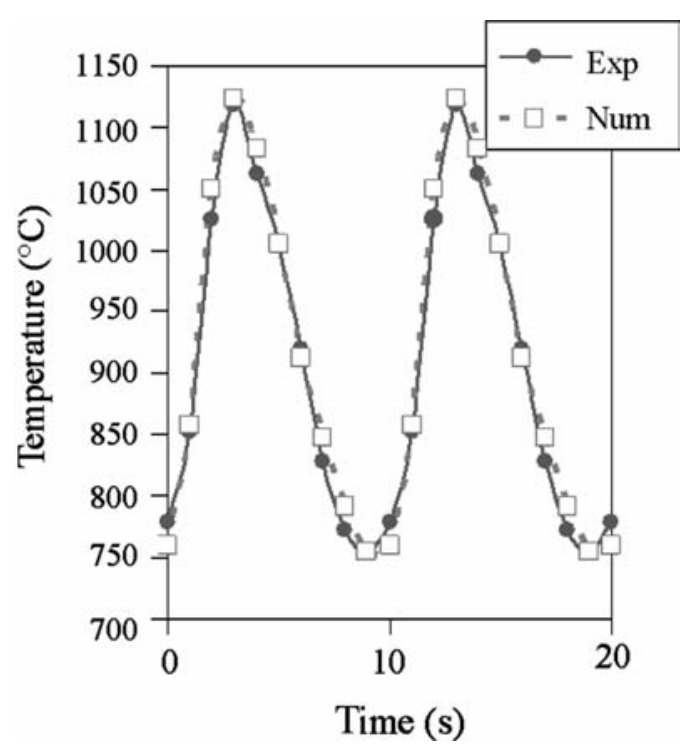

Figure 8. Experimental and numerical thermal cycles in the center part of the specimen. 
Based on the temperature field thus obtained, mechanical calculations have then been achieved to determine the thermomechanical cycles imposed to the specimens. Whatever the type of specimens (with or without coating), stresses are strongly biaxial with a predominance of longitudinal $\left(\sigma_{z z}\right)$ and tangential $\left(\sigma_{t t}\right)$ stresses. Other components are insignificant. For each transverse section of the specimen, the thermomechanical cycle is different due to the strong temperature gradients along a generatrix. Moreover, for each section, stresses are different from the inside to the outside of the specimen. In the following, attention will be paid to the central section of the specimens, where the loading is the more critical. At last, it can be interesting to indicate that the stability of stress evaluation with respect to thermal loading has been studied: a slightly different temperature field $\left(\Delta T \approx 10^{\circ} \mathrm{C}\right.$ for peak value) induces slightly different calculated stress values $(\approx 10 \mathrm{MPa})$ but strictly similar thermomechanical cycle shape.

Figures 9 and 10 show the results obtained in the central section of a specimen without any coating, respectively for the external and internal surfaces. An internal surface is essentially loaded in compression: stress range is about $400 \mathrm{MPa}$ for longitudinal stress and $300 \mathrm{MPa}$ for tangential stress. Tensile stresses are predominant for the external surface with a stress range of about $200 \mathrm{MPa}$ for both components. As a consequence, it seems that the most damaging cycle in terms of thermomechanical fatigue occurred inside the specimen (higher stress at highest temperature). This is fully consistent with the experimental observations that showed that

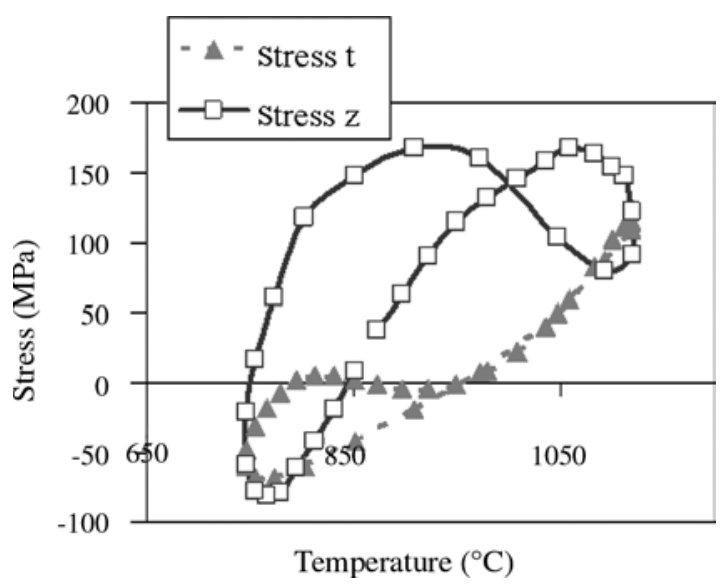

Figure 9. Thermomechanical cycle of external surface - without coating (longitudinal and tangential stresses). 


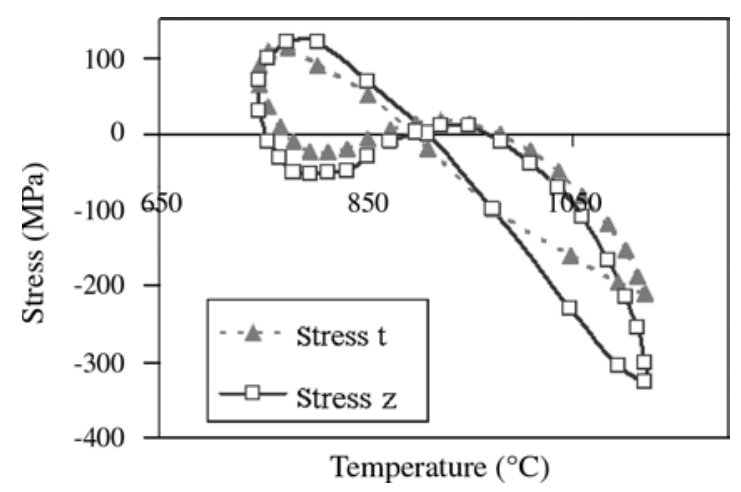

Figure 10. Thermomechanical cycle of internal surface - without coating (longitudinal and tangential stresses).

superficial cracking was more important on the internal surface. In addition, this result is in good agreement with the difference in the coalescence direction of $\gamma^{\prime}$ precipitates observed in Figures 4 and 5. Compression leads to a coalescence parallel to the stress axis while tensile stresses gather the precipitates along a direction perpendicular to the stress, that is to say, perpendicular to the external surface (Engler-Pinto and Rezaï-Aria, 2000).

For coated specimens, thermomechanical cycles of the internal and external surfaces (i.e., in the coating) are presented in Figures 11 and 12. It appears that the loading is compression loading. This can be explained by the higher thermal expansion coefficient of the coating compared to the substrate. At a high temperature, the coating tends to extend more than the substrate; as the substrate is predominant, it imposes the displacement and this results in compression in the coating. The most damaging cycle is once more in the internal surface of the specimen with a maximum stress of $440 \mathrm{MPa}$ (to be compared to $320 \mathrm{MPa}$ for the specimen without a coating). In the substrate, thermomechanical cycles are very similar to what is observed for non-coated specimens, alternating tensile and compression stresses, but with a lower mean stress.

For a first approach, numerical modeling gives interesting information that is consistent with experimental results: for both type of specimens, it shows that the critical site is located in the internal surface (where damage appears) and that compression is predominant on the internal surface while tensile stresses are more important on the external surface. This last point can be related to the observations of the microstructure. However, the so-calculated thermomechanical cycles cannot fully explain the detrimental effect of coating. Actually, some aspects of the complex loading and its 


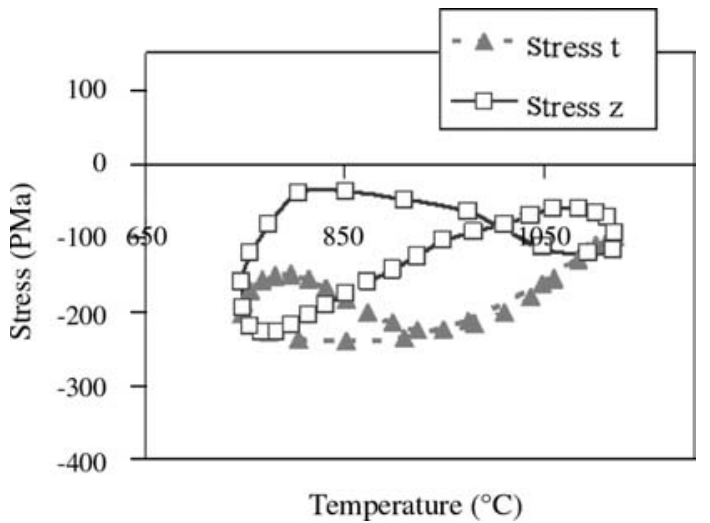

Figure 11. Thermomechanical cycle of external surface - with coating (longitudinal and

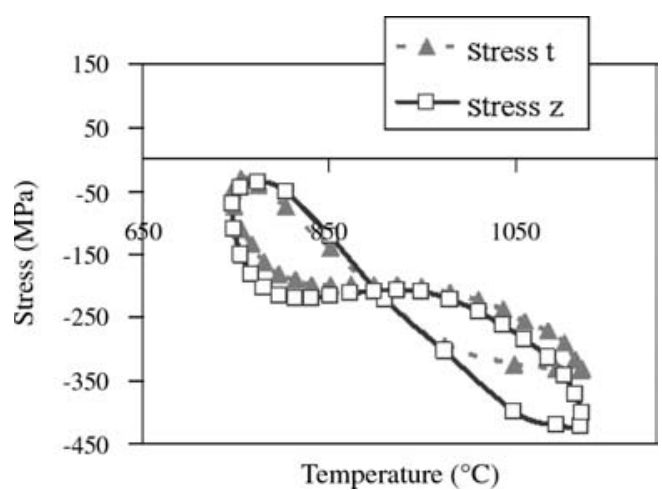

Figure 12. Thermomechanical cycle of internal surface - with coating (longitudinal and tangential stresses).

chemical consequences are missing in the modeling to consider that numerical results are completely reliable:

- for the non-coated specimens, the area of $\gamma^{\prime}$ phase depletion is not taken into account

- interface between substrate and coating and subsequent mechanical properties transition are not well represented

- the coating has been assumed elastic despite the high temperature.

Nevertheless, some damage mechanisms linked to the presence of the coating can be proposed. To explain coating failure under compression cycles, it is first important to note that no damage to the coating was observed after only 1000 cycles. Thus, failure did not occur under 
monotonic loading. However, at a high temperature, ductility of the coating alloy induces plasticity (Boudot, 1999) that could lead to tensile stresses during cycling, where strains are imposed by the substrate, and provoke cracking of the coating layer. This hypothesis could easily be checked by introducing plastic behavior in numerical modeling. Concerning cracking through the substrate under the coating, two mechanisms can be considered. The first one is based on localized oxidation due to coating failure. This mechanism has already been observed by Rémy et al. (2000). The second one is based on the stress concentration induced by the cracks in the coating. To study this last hypothesis, it is necessary to know the mechanical properties of the interface to evaluate the load transfer from the coating to the substrate. If we now consider the no-cracking of the non-coated specimen, we must remember the presence of a $\gamma^{\prime}$ phase depletion zone related to the effects of oxidation and loading. Cyclic behavior of this weakened part of material whose elastic limit is lower could lead to lower stresses compared to the calculated ones, assuming the displacement is imposed by the rest of the substrate. Subsequently, damage due to plastic strain would be predominant and could lead to a higher number of cycles before failure, compared to the one corresponding to crack propagation in the initial substrate with coating. To check the validity of this hypothesis, monotonic and thermomechanical fatigue tests on a fully weakened material are needed. Mechanical properties of such a material will then be known and could be introduced in the numerical modeling. Comparing the results of numerical thermomechanical cycles and tests would help to conclude on the influence of the $\gamma^{\prime}$ phase depletion zone on the thermomechanical fatigue resistance.

As a conclusion, it seems necessary to study more precisely the cyclic behavior of the coating and oxidation effect on the substrate to fully describe the damage mechanisms related to thermomechanical fatigue.

\section{CONCLUSIONS}

The use of a special device for thermomechanical fatigue tests and of its coupled numerical modeling has allowed the study of the influence of a NiCoCrAlYTa coating on the thermomechanical fatigue resistance of nickel-base superalloy MC2. A specimen tested with this specific rig is submitted to different thermomechanical cycles during one test changing with the position on the specimen. Moreover, loading consists in biaxial stresses which is close to what occurs for the studied applications. At last, comparison with the numerical simulation permits a critical analysis of modeling employed for structural design. In the present work, experimental results show a detrimental effect of the coating. Numerical simulations gave 
interesting information that is consistent with experimental results. This led to propose damage mechanisms related to the presence of a coating. However, mechanical properties associated with chemically modified areas (such as the $\gamma^{\prime}$ phase depletion zone and the interface coating/substrate) are missing and thus cannot fully exploit the numerical modeling and confirm the hypothesis on the damage mechanisms.

\section{REFERENCES}

Boudot, A. (1999). Properties of High Temperature Protective Coating Used for HP Turbine Blades, PhD Thesis in Materials Science, University Paul Sabatier, Toulouse, France (in French).

Engler-Pinto, C.C. and Rezaï-Aria, F. (2000). Thermo-mechanical Fatigue Investigation of Single Crystal Nickel Base Superalloy SRR99, In: Sehitoglu, H. and Maier, H.J. (eds), Thermomechanical Fatigue Behaviour of Materials: Third Volume, ASTM STP 1371, pp. 319-332, American Society for Testing and Materials, West Conshohocken, PA.

Kowalewski, R. and Mughrabi, H. (2000). Thermo-mechanical and Isothermal Fatigue of a Coated Columnar-grained Directionally Solidified Nickel-based Superalloy, In: Sehitoglu, H. and Maier, H.J. (eds), Thermomechanical Fatigue Behaviour of Materials: Third Volume, ASTM STP 1371, pp. 3-17, American Society for Testing and Materials, West Conshohocken, PA.

Lautridou, J.C., Guedou, J.Y. and Delautre, J. (1996). Comparison of Single Crystal Superalloys for Turbine Blade through TMF Tests, In: Bressers, J. and Rémy, L. (eds), Fatigue Under Thermal and Mechanical Loading, Mechanisms, Mechanics and Modelling, Proceedings of the Symposium held at Petten, The Netherlands, Kluwer Academic Publishers, Dordrecht, The Netherlands, 22-24 May 1995, pp. 141-149.

Merval, A. (2002). Thermomechanical Fatigue Modelling of Coated Superalloy Samples, Research Master in Mechanical Engineering, University Paul Sabatier, Toulouse, France (in French).

Paun, F. (1998). New Type of Experimental Method in Thermo-mechanical Fatigue of Materials with a High Cycling Frequency, PhD Thesis in Mechanical Engineering, University Paul Sabatier, Toulouse, France (in French).

Paun, F. and Chieragatti, R. (2000). A New Technique for High Frequency Multiaxial Thermomechanical Fatigue Testing of Materials, In: Sehitoglu, H. and Maier, H.J. (eds), Thermomechanical Fatigue Behaviour of Materials: Third Volume, ASTM STP 1371, pp. 150-164, American Society for Testing and Materials, West Conshohocken, PA.

Rémy, L., Chataigner, E. and Fleury, E. (1996). Modelling of the Thermal-mechanical Fatigue Behaviour of Coated and Bare Nickel-base Superalloy Single Crystal AM1, In: Bressers, J. and Rémy, L. (eds), Fatigue Under Thermal and Mechanical Loading, Mechanisms, Mechanics and Modelling, Proceedings of the Symposium held at Petten, The Netherlands, Kluwer Academic Publishers, Dordrecht, The Netherlands, 22-24 May 1995, pp. 381-392.

Rémy, L., Koster, A., Chataigner, E. and Bickard, A. (2000). Thermal-mechanical Fatigue and the Modelling of Materials Behaviour Under Thermal Transients, In: Sehitoglu, H. and Maier, H.J. (eds), Thermomechanical Fatigue Behaviour of Materials: Third Volume, ASTM STP 1371, pp. 223-238, American Society for Testing and Materials, West Conshohocken, PA.

Zamrik, S.Y. and Renauld, M.L. (2000). Thermo-mechanical Out-of-phase Fatigue Life of Overlay Coated IN-738LC Gas Turbine Material, In: Sehitoglu, H. and Maier, H.J. (eds), Thermomechanical Fatigue Behaviour of Materials: Third Volume, ASTM STP 1371, pp. 119-137, American Society for Testing and Materials, West Conshohocken, PA. 